\title{
Disease of the Year: Differential Diagnosis of Uveitic Macular Edema
}

\section{Aniruddha Agarwal, Francesco Pichi, Alessandro Invernizzi \& Vishali Gupta}

To cite this article: Aniruddha Agarwal, Francesco Pichi, Alessandro Invernizzi \& Vishali Gupta (2018): Disease of the Year: Differential Diagnosis of Uveitic Macular Edema, Ocular Immunology and Inflammation, DOI: 10.1080/09273948.2018.1523437

To link to this article: https://doi.org/10.1080/09273948.2018.1523437

$$
\text { 曲 Published online: } 01 \text { Oct } 2018 .
$$

Submit your article to this journal 중

View Crossmark data \lceil 


\title{
Disease of the Year: Differential Diagnosis of Uveitic Macular Edema
}

\author{
Aniruddha Agarwal $\oplus^{1}$, Francesco Pichi ${ }^{2,3}$, Alessandro Invernizzi $\oplus^{4,5}$, and Vishali Gupta ${ }^{1}$ \\ ${ }^{1}$ Department of Ophthalmology, Advanced Eye Center, Post Graduate Institute of Medical Education and \\ Research, Chandigarh, India, ${ }^{2}$ Cleveland Clinic Abu Dhabi, Eye Institute, Abu Dhabi, United Arab Emirates., \\ ${ }^{3}$ Cleveland Clinic Lerner College of Medicine, Case Western Reserve University, Cleveland, Ohio, USA, ${ }^{4}$ Eye \\ Clinic, Department of Biomedical and Clinical Science 'Luigi Sacco', Luigi Sacco Hospital, University of \\ Milan, Milan, Italy, and ${ }^{5}$ Department of Ophthalmology, Save Sight Institute, University of Sydney, Sydney, \\ New South Wales, Australia
}

\begin{abstract}
Uveitic cystoid macular edema (UME) is an important cause of visual morbidity among patients with both infectious and non-infectious uveitis. UME may be associated in more than $30 \%$ cases of active uveitis. However, even patients with minimal features of intraocular inflammation may develop recurrent or chronic UME. Therefore, the evaluation and management of UME in patients with uveitis may be challenging. A number of vitreoretinal pathologies may result in UME and accumulation of fluid in the intra- or subretinal space. These need to be carefully distinguished from each other so that appropriate management can be initiated. All types of uveitis, including anterior uveitis (where the primary site of inflammation is not in the posterior segment) can present with UME. Other conditions such as diabetes, and surgery, can present with macular edema. This index review highlights various differential diagnoses of UME and provides illustrative case examples with multimodal imaging evaluation.
\end{abstract}

Keywords: Macular edema, optical coherence tomography, fluorescein angiography, CME, retinal thickness

Uveitic cystoid macular edema (UME) is a major cause of visual morbidity among patients with both, infectious and non-infectious uveitis. More than 30\% patients with uveitis can develop serious sight-threatening vision loss due to UME. ${ }^{1-3}$ The prevalence of $\mathrm{UME}$ is more common with posterior uveitis. However, any form of inflammation in the eye, including anterior uveitis (AU), can lead to UME. Chronic forms of uveitis, such as birdshot chorioretinopathy, sarcoidosis, and Behcet's disease are highly likely to develop persistent and often refractory UME.

Since chronic UME is a significant cause of permanent visual impairment, it needs careful evaluation, and identification of the pro-inflammatory factors leading to development of UME. Recurrent or nonresponsive UME could indicate breakdown of the blood-retinal barrier, increased local inflammatory mediators, vascular compromise/hyperpermeability, or dysfunction of the retinal pigment epithelial (RPE) pump mechanism. It is relevant to ascertain the cause of UME, recognize specific clinical entities, and identify UME associated with idiopathic uveitis, so that appropriate therapy can be instituted. Early diagnosis and therapy prevent long-term photoreceptor and RPE cell damage, and help in preserving visual acuity in these patients. ${ }^{1,2}$

Among patients with uveitis, there may be other causes leading to presence of intra- or subretinal fluid. For instance, inflammatory macular edema may occur in patients after surgical intervention (such as post-cataract surgery macular edema). There may be other conditions that mimic UME, such as drug-induced maculopathies. Rarely, retinal dystrophies may be associated with ocular inflammation and UME. Therefore, a

Received 25 May 2018; revised 5 September 2018; accepted 10 September 2018

Correspondence: Vishali Gupta, Ophthalmology, Advanced Eye Center, Post Graduate Institute of Medical Education and Research (PGIMER), Sector 12, Chandigarh 160012, India. E-mail: vishalisara@yahoo.co.in

Color versions of one or more of the figures in the article can be found online at www.tandfonline.com/ioii. 
complete history, examination, and evaluation using multimodal imaging including optical coherence tomography (OCT), fluorescein angiography (FA), and other tools is necessary to accurately diagnose UME.

In the index review, various differential diagnoses of UME including uveitic and non-uveitic causes have been described with illustrative case examples. The relevance of various imaging techniques in the evaluation of UME such as FA, OCT, and wide-field imaging has been thoroughly explained.

\section{ROLE OF IMAGING IN THE DIFFERENTIAL DIAGNOSIS OF MACULAR EDEMA}

UME may be diagnosed clinically using macular contact lens or careful slit-lamp biomicroscopy. However, in the era of advanced imaging diagnostics, various imaging tools such as OCT and FA are preferred for making an accurate diagnosis. OCT has distinct advantages such as its ability of detecting concomitant pathologies such as abnormal vitreomacular tractions, epiretinal membranes, and macular detachment. FA, on the other hand, helps in the evaluation of macular perfusion and regularity of the foveal avascular zone.

\section{Fluorescein Angiography}

FA is very useful in determining the true location of the inflammation, disease activity, and involvement of retinal vasculature and optic disc. FA helps in the detection of level and severity of intraocular inflammation, presence of active choroiditis/retinitis lesions, and quantification of retinal vascular (venular/arteriolar or capillary) leakage. These findings aid the clinician in arriving at an etiological diagnosis. Thus, FA plays a central role in the management of uveitis and various other conditions that mimic ocular inflammations such as masquerade syndromes (for example, intraocular lymphoma). Leakage on FA can be further characterized as macular or peripheral and based upon the vessel of origin, it can be classified as small, medium, or large vessel leakage. ${ }^{3-5}$

Recognition of perifoveal/macular leakage is relevant because the status of the macular vasculature can have a direct relationship with the visual morbidity. Leakage may be restricted to the region of the foveal avascular zone or it may extend well beyond to involve the parafoveal region. In the early phase of the FA, macular leakage may have a subtle appearance as a faint hyperfluorescence. Therefore, venous or late phase of the FA is relevant to determine the exact extent of leakage and hyperfluorescence. An assessment of the late FA frames can help in determining the presence of vascular as well as macular leakage suggestive of UME. Angiographic presence of leakage and UME is an indicator of ongoing inflammation and breakdown of blood-retinal barrier, requiring treatment.

Attempts have been made to determine the relationship between fluorescein angiographic leakage at the macula and the visual acuity. Studies have shown that presence of angiographic UME at the initial visit may be related to the visual prognosis in entities such as Behcet's disease. ${ }^{6}$ Other features on FA such as retinal vascular leakage and optic disc hyperfluorescence are also significantly associated with worse initial visual acuity. ${ }^{7}$ Hence, at baseline, assessment using FA not only helps in determining disease activity, but also in the prediction of visual recovery following treatment of UME.

The introduction of ultra-wide field (UWF) FA has revolutionized the management of various conditions such as posterior uveitis and diabetic retinopathy. UWF FA provides significant additional information over conventional FA helping in changing management decisions such as modifications of therapeutic interventions. In the context of UME, UWF FA imaging has been shown to be useful in correlating vascular leakage with macular thickness. Eyes with peripheral vascular leakage on UWF FA are likely to have UME at baseline, requiring more aggressive therapy. ${ }^{8}$ Similarly, another study of 82 uveitis patients undergoing UWF FA showed that peripheral leakage is associated with central macular leakage. ${ }^{9}$ UWF FA is very helpful in determining the presence of occlusive vasculitis and for the quantification of the true extent of the capillary non-perfusion. Areas of retinal ischemia and neovascularization can be easily identified using UWF FA, aiding in decision for targeted laser photocoagulation. ${ }^{10-12}$ In summary, FA imaging greatly aids in the detection and follow-up of UME related to uveitis as well as other diseases affecting the retinochoroidal tissue.

\section{Optical Coherence Tomography}

OCT provides in vivo near-histological cross-sectional images of the retina and the choroid permitting detailed analysis of the pathology affecting various structural layers. OCT allows non-invasive monitoring of the retinal thickness and edema, along with presence of intra- or subretinal fluid that occurs due to breakdown of the blood-retinal barrier in various pathologies. OCT permits highly reproducible monitoring of the retinochoroid during treatment of UME. Precise monitoring of the retinal thickness is possible by using follow-up scan protocols that capture images of the exact same location as the previous visit. Presence of significant retinal thickening with edema and fluid is associated with poor visual acuity. ${ }^{3-5,13}$ 
With the introduction of higher resolution OCT such as spectral-domain OCT (SD-OCT), it has become possible to further characterize the type and morphology of edema and UME, and improve the prediction of visual recovery in these patients. Using high-resolution OCT, it is possible to document and measure the central retinal thickness and the area of serous macular detachment with greater precision. In addition, better delineation of outer retinal layers such as the external limiting membrane, and the ellipsoid and myoid zones is possible with the OCT. The integrity of the outer retinal layers and RPE is directly correlated with the central visual acuity recovery. Disruption of the outer retinal layers can seriously compromise the visual recovery despite resolution of the intra- or subretinal fluid. ${ }^{14,15}$

OCT has become the gold standard in the diagnosis of UME. Using OCT, it is possible to classify the patterns of UME qualitatively. In 2004, Markomichelakis et al. performed a cross-sectional study in 84 eyes of 60 patients with UME. The authors observed three patterns of UME, i.e. diffuse pattern, cystoid macular edema (CME), and serous retinal detachment. ${ }^{13}$ Eyes with cystoid type of edema had a higher probability of visual improvement. ${ }^{16}$ In addition, OCT can aid in the detection of additional conditions leading to higher macular thickness in uveitis, such as presence of concomitant epiretinal membranes or vitreomacular traction, as well as presence of inflammatory choroidal neovascular membranes. More than $30 \%$ patients with UME may have associated epiretinal membranes. ${ }^{13}$

Various studies have compared the utility and advantages of OCT over FA in the management of UME. Antcliff et al. ${ }^{17}$ compared OCT and FA in over 100 patients with UME. The authors observed that OCT was as effective as FA in detecting UME. However, OCT is superior in identification of the axial distribution of fluid; for instance, detection of subretinal fluid (SRF) is possible using OCT. OCT has a high sensitivity and specificity in detection of UME compared to FA. Thus, while FA and OCT are both very useful techniques in diagnosing UME, the two modalities complement each other and provide a different set of information that helps in comprehensive evaluation of the patient. When used independently, there may be certain discrepancies in the detection of fluid. ${ }^{18}$ Therefore, a combination of OCT and FA may provide highly precise, reproducible and comprehensive evaluation of the UME (both quantitative and qualitative) in eyes with uveitis.

\section{COMMON CAUSES OF UVEITIC MACULAR EDEMA}

\section{Anterior Uveitis}

The classification of uveitis proposed by the first international workshop on standardization of Uveitis
Nomenclature (SUN) defines an AU as an ocular inflammatory process having the anterior chamber of the eye as primary site of inflammation. ${ }^{19}$ Patients affected by AU can develop UME though, by definition, there is no posterior segment disease. Even when detected, the presence of UME does not change the classification of AU, because it is considered a complication and not the primary location of the inflammatory process.

HLA-B27-associated acute AU is the most common cause of AU representing the $18-32 \%$ and the $6-13 \%$ of all AU cases in western countries and in Asia, respectively. The incidence of UME among HLA-B27 uveitis patients has been reported to be 6-30\% depending on the studied population. ${ }^{20}$ While HLAB27 AU is characterized by specific features and a higher incidence of certain complications, the incidence of UME seems to be similar in HLA-B27- and non-HLA-B27-related AU. ${ }^{21}$ Viral induced-AU however seem to be less commonly complicated by UME, with the presence of fluid in the macular area being rarely reported in these entities. ${ }^{22,23}$ Finally, UME is virtually absent in Fuchs' iridocyclitis, a specific type of AU mainly caused by rubella virus infection, thus helping in the differential diagnosis of Fuchs's with other similar entities. ${ }^{24}$

No significant differences in the incidence of UME between the normal population and uveitic eyes undergoing cataract surgery after 3 months without signs of active inflammation have been reported. ${ }^{25}$ However, several studies suggest that eyes affected by uveitis, including anterior form of uveitis, are more likely to develop UME or to have UME recurrence after cataract surgery. ${ }^{25-27}$ This is particularly true for chronic forms of $\mathrm{AU}$, such as uveitis related to juvenile idiopathic arthritis, that has been reported to have up to $55 \%$ incidence of UME after cataract surgery. ${ }^{28}$

\section{Intermediate Uveitis and Pars Planitis}

The SUN classifies intermediate uveitis (IU) as an inflammatory condition where the vitreous is the major site of inflammation. Often the primary vitreous involvement is accompanied by peripheral vascular sheathing and UME. ${ }^{19}$ The majority of cases of IU are of idiopathic etiology and are usually referred as pars planitis. This is a non-granulomatous bilateral uveitis occurring in young individuals with a higher prevalence between 15 to 35 years of age. As the majority of pediatric patients with uveitis have an indeterminate cause (with no systemic involvement), pars planitis is most often diagnosed in this patient population. However, the association of IU with several autoimmune and infectious diseases such as multiple sclerosis, sarcoidosis, tuberculosis, and Lyme 
disease has been reported in the literature. ${ }^{29}$ It is imperative to suspect multiple sclerosis in patients with IU, to avoid delays in the diagnosis of the systemic disease. Baseline neuroimaging be performed to rule out white matter lesions of the central nervous system.

IU is usually a benign inflammatory condition but its complications if untreated can lead to severe visual loss. UME, with an incidence ranging from $12 \%$ to $51 \%$ depending on the studied population, is the most common cause of visual loss in these entities. ${ }^{30}$ The detection of a visual impairing macular edema plays a key role in the management of IU. In fact, while cases with IU can be managed with observation alone (if the inflammation is mild), treatment needs to be initiated promptly in the presence of vision-threatening complications such as UME. ${ }^{29}$

\section{Retinal Vasculitis}

Retinal vasculitis is characterized by inflammation of the retinal venules, arterioles and/or capillaries with perivascular sheathing or cuffing, vascular leakage, and/or occlusion. There may be signs of retinal ischemia, including cotton-wool spots and intra-retinal hemorrhages, as well as UME. Retinal vasculitis may be associated with various infectious etiologies such as tuberculosis, syphilis, Lyme's disease, cat-scratch disease, among others, and non-infectious etiologies such as sarcoidosis, Birdshot chorioretinopathy, Behcet's disease, as well as IU / pars planitis. ${ }^{31-33}$

Retinal vasculitis may be associated with type III hypersensitivity reaction and focal, segmental or diffuse retinal perivascular proliferation of lymphoplasmacytic infiltrates. ${ }^{31}$ Retinal vasculitis is also characterized by a breakdown of blood-retinal barrier secondary to intraocular or systemic inflammation resulting in macular edema and intra-/subretinal fluid accumulation. Increased expression of cell adhesion molecules along retinal vessels and blood-retinal barrier cells plays an important role in inflammatory cell recruitment. Excessive inflammation may also result in an occlusive form of vasculitis characterized by development of retinal neovascularization and high rates of ocular complications. ${ }^{34}$

Although there is a large pathological diversity among the retinal vasculitis etiologies, the manifestations of inflammatory changes resemble in many ways. Patients with active retinal vasculitis may have reduced visual acuity due to presence of central macular edema. ${ }^{35}$ Retinal thickening can be observed on FA as leakage of dye in the macula or presence of a diffuse hyperfluorescence increasing toward the late phase. ${ }^{36}$ This must be differentiated from an increase in the macular leakage following laser photocoagulation performed for retinal ischemia. Common diseases associated with retinal vasculitis and UME include intraocular tuberculosis, ${ }^{37,38}$ Behcet's disease, ${ }^{39}$ Birdshot chorioretinopathy, ${ }^{40}$ and sarcoidosis. ${ }^{41,42}$

Non-inflammatory retinal vein occlusion (either central or branch retinal vein occlusion) associated with macular edema closely parallels inflammatory retinal vascular occlusion. However, both central and branch retinal vein occlusions (CRVO and BRVO) are not associated with clinically appreciable vascular sheathing, vitritis, or other signs of inflammation. FA does not show early vascular leakage, but may show only late staining of the occluded vessels. ${ }^{34}$

\section{Choroiditis and Chorioretinitis}

When the primary site of inflammation is the choroid or the retina, the uveitis is typically classified as choroiditis or chorioretinitis. ${ }^{19}$ These entities can have an autoimmune or an infectious cause with specific features characterizing the different forms and helping in the differential diagnosis. ${ }^{43}$ The main causes include toxoplasmic chorioretinitis, ${ }^{44}$ sarcoid choroiditis, ${ }^{41}$ birdshot chorioretinopathy, ${ }^{45}$ syphilis, $^{46}$ tuberculous posterior uveitis, ${ }^{47}$ Vogt-Koyanagi-Harada (VKH) disease $^{48}$ multifocal choroiditis, ${ }^{49}$ serpiginous choroiditis, ${ }^{50}$ and punctate inner choroidopathy. ${ }^{49,51,52}$

UME can occur in both infectious and autoimmune choroiditis/chorioretinitis as a complication of the inflammatory process (Figure 1A). ${ }^{1}$ Cystic spaces resulting from a disruption of the retinal layers deriving from direct tissue damage can also be seen and have to be distinguished from UME which is caused by a breakdown of the blood-retinal barrier (Figure 1B). ${ }^{53,54}$

Choroiditis and chorioretinitis can be complicated by inflammatory choroidal neovascularization more often than other uveitis entities. ${ }^{55}$ The exudative process linked to the presence of inflammatory choroidal neovascularization often leads to the formation of cystic changes within the retinal tissue overlying the lesion (Figure 1C). This particular form of intraretinal fluid is related to the inflammatory choroidal neovascular activity, can be present in absence of active inflammation, and needs a different treatment strategy, often combining anti-inflammatory drugs with anti-vascular endothelial growth factors in order to control the neovascularization rather than the inflammation alone. ${ }^{56}$

\section{Panuveitis}

Uveitis having diffuse inflammation involving the anterior chamber, the vitreous and the retinochoroidal region are named panuveitis. ${ }^{19}$ Majority of the times, these entities are associated with systemic diseases 


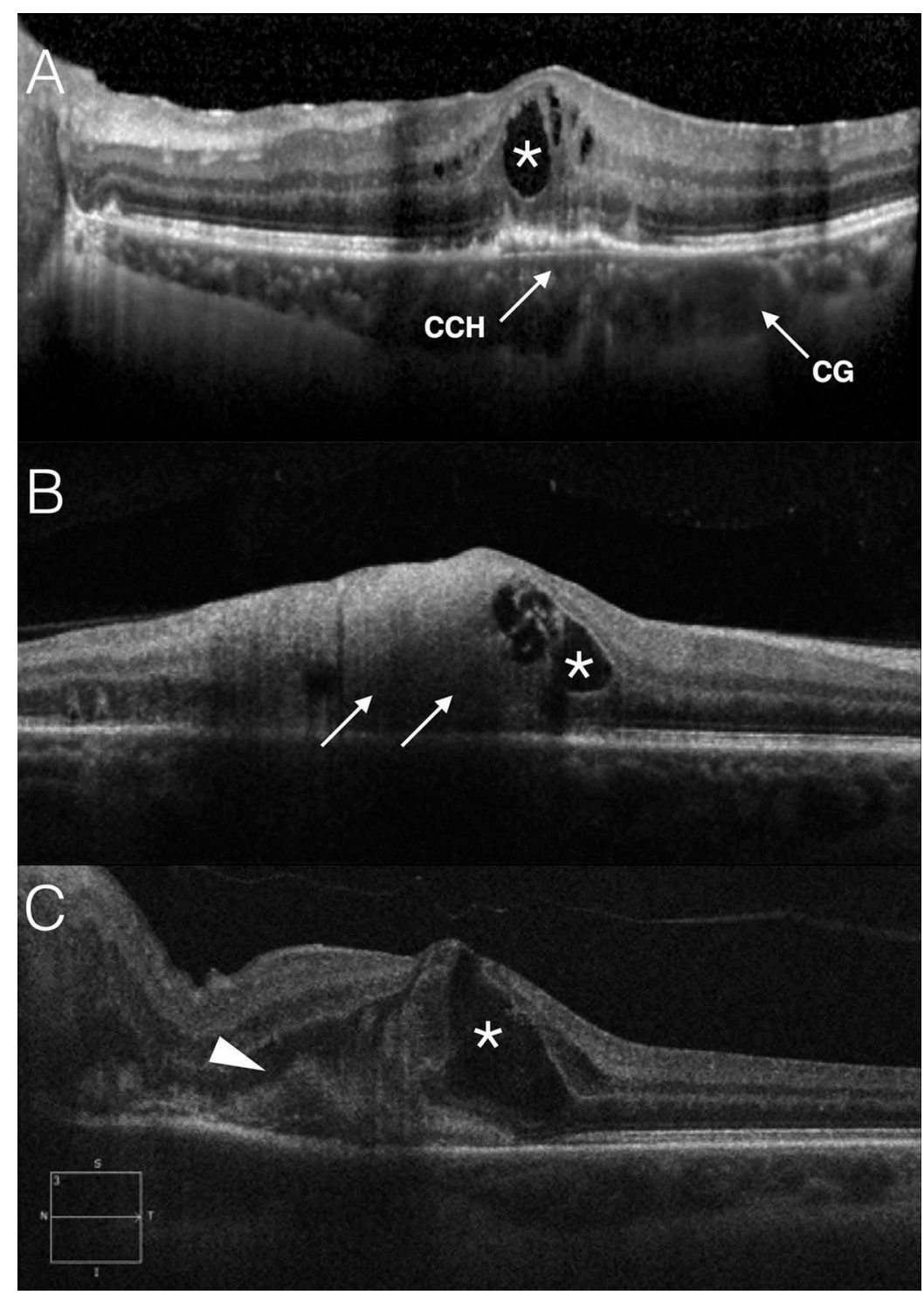

FIGURE 1. Optical coherence tomography (OCT) scans demonstrating Cystoid macula edema in choroiditis and chorioretinitis. (A).Cystoid macular edema (white asterisk) complicating a case of tubercular choroiditis. A choroidal granuloma (CG) is clearly visible in the choroidal stroma in the perifoveal region along with an area of choriocapillaris hypo-perfusion $(\mathrm{CCH})$ right underneath the fovea.

(B).Cystic spaces within the retina (white asterisk) are visible along the edges of a patch of toxoplasmic chorioretinitis (white arrows). The formation of these spaces is usually related to a direct damage to the retinal tissue structure rather than to a breakdown of the blood-retinal barrier.(C).

Intraretinal cystic accumulation of fluid (white asterisk) as part of the exudative process secondary to the presence of an inflammatory choroidal neovascularization (white arrowheads) in a patient affected by sarcoid chorioretinitis.

and are accompanied by manifestations outside the eye. The most common panuveitis are caused by sarcoidosis, ${ }^{41}$ tuberculosis, ${ }^{47}$ Bechet's disease, ${ }^{57}$ syphilis, ${ }^{46}$ and VKH disease. ${ }^{48}$

UME can occur in panuveitis with a variable incidence which is usually directly correlated with the duration and the amount of intraocular inflammation (Figure 2A). ${ }^{1}$ UME is such a common finding in chronic panuveitis that its absence in case of a chronic inflammation of unknown origin should rise the suspect of a masquerade syndrome such as an intraocular lymphoma. ${ }^{58}$
Similar to choroiditis and chorioretinitis, panuveitis can show disruption of the retinal layers mimicking UME and can be complicated by inflammatory choroidal neovascularization (though it is pertinent to note that inflammatory choroidal neovascularization may rarely lead to intraretinal cystic changes).$^{55}$ Epiretinal membranes and vitreomacular tractions are also a common complication of panuveitis as a result of the combined vitreoretinal inflammation (Figure 2B). Such epiretinal membranes can induce the formation of tractional UME which can be particularly resistant to pharmacological treatment and may require a surgical approach. ${ }^{13}$ 


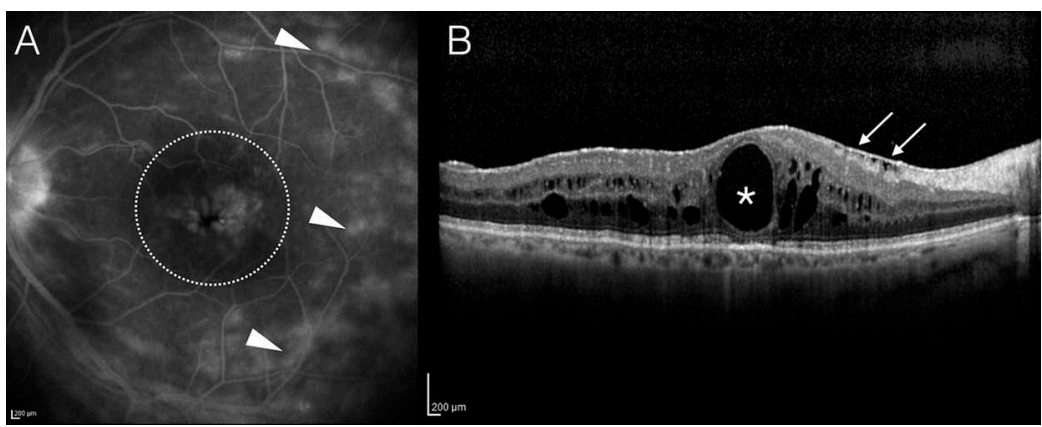

FIGURE 2. Cystoid macular edema in panuveitis.

(A).Cystoid macular edema (dotted circle) complicating a case of sarcoid panuveitis. Areas of chronic breakdown of the blood-retinal barrier are visible on fluorescein angiography (white arrowheads).

(B).Optical coherence tomography (OCT) scan of the posterior pole showing a Diffuse cystoid macular edema with macrocyst (white asterisk) in a patient with chronic tubercular panuveitis. A thick epiretinal membrane complicating the picture is clearly visible (white arrows)

\section{Scleritis}

Scleritis is an immune-mediated chronic inflammatory process that involves the sclera and is often associated with systemic disorders. Anterior scleritis is the most common anatomical location of scleritis and can be further classified as nodular, diffuse, necrotizing with inflammation, and necrotizing without inflammation (scleromalacia). Entities such as rheumatoid arthritis, polychondritis, granulomatosis with polyangiitis, and polyarteritis nodosa, among others, may be associated with this condition, requiring chronic systemic therapy with steroids and/or immunomodulatory agents. ${ }^{59,60}$

Macular edema is a rare complication of scleritis. In a series published by Bernauer et al., of the 40 patients with a 5-year follow-up, UME was observed in 6 eyes (11\%). The authors observed that UME was fully reversible after high-dose oral steroids. ${ }^{61}$ Similarly, Pavesio et al., in their review of systemic disorders associated with scleritis, noted that UME is a rare complication of scleritis with an increased risk of vision loss and intraocular inflammation (sclerouveitis) ${ }^{62}$

\section{DIFFERENTIAL DIAGNOSIS OF NON- UVEITIC MACULAR EDEMA}

\section{Macular Hole and Vitreomacular Traction}

Macular holes are full-thickness defects of the retinal tissue affecting the anatomical fovea. Macular holes are common among females with peak incidence in the sixth-seventh decade of life. Most macular holes are idiopathic in nature, but some may be caused due to trauma or can be associated with myopia. It is now widely accepted that various tangential and anteroposterior tractional forces at the vitreoretinal interface may play a role in the pathogenesis of macular hole.
In addition, there have been histopathological reports that suggest cystoid changes that occur in the retinal tissues leading to development of a full-thickness hole. ${ }^{63-65}$

Macular holes typically present with a well-defined rounded excavation of retinal tissue in the central macula. However, these holes can have associated retinal thickening, intraretinal fluid, and macular edema. There may be an associated cuff of SRF. At the margins of the hole, cystic changes are fairly common and these can be easily detected using OCT imaging. Occasionally, there may be associated epiretinal membranes resulting in fine crinkling. ${ }^{64,66,67}$ Therefore, in the evaluation of a macular hole, it is imperative to analyze the OCT scans carefully, especially in situations where the size of the hole is small. Small macular holes may be missed if all the OCT scans are not evaluated (Figure 3).

Abnormal vitreoretinal tractional forces may lead to the development of both, macular edema as well as macular holes. In patients with chronic macular edema, exacerbation of centripetal vitreomacular tractional forces may lead to development of macular pseudoholes or lamellar macular holes. ${ }^{68}$ These may occur following interventions such as intravitreal injections of anti-VEGF agents or other drugs such as steroid implants. ${ }^{68-71}$ Usually, such lamellar holes develop from chronic macular edema in the presence of abnormal vitreoretinal traction or epiretinal membranes. However, lamellar holes have been shown to form in eyes with chronic macular edema despite complete separation of posterior hyaloid and absence of epiretinal membranes. ${ }^{72}$ The exact mechanism of hole development in such eyes is unclear.

\section{Drug-Induced Maculopathies}

A number of systemically administered drugs can result in toxicity affecting various ocular tissues. 

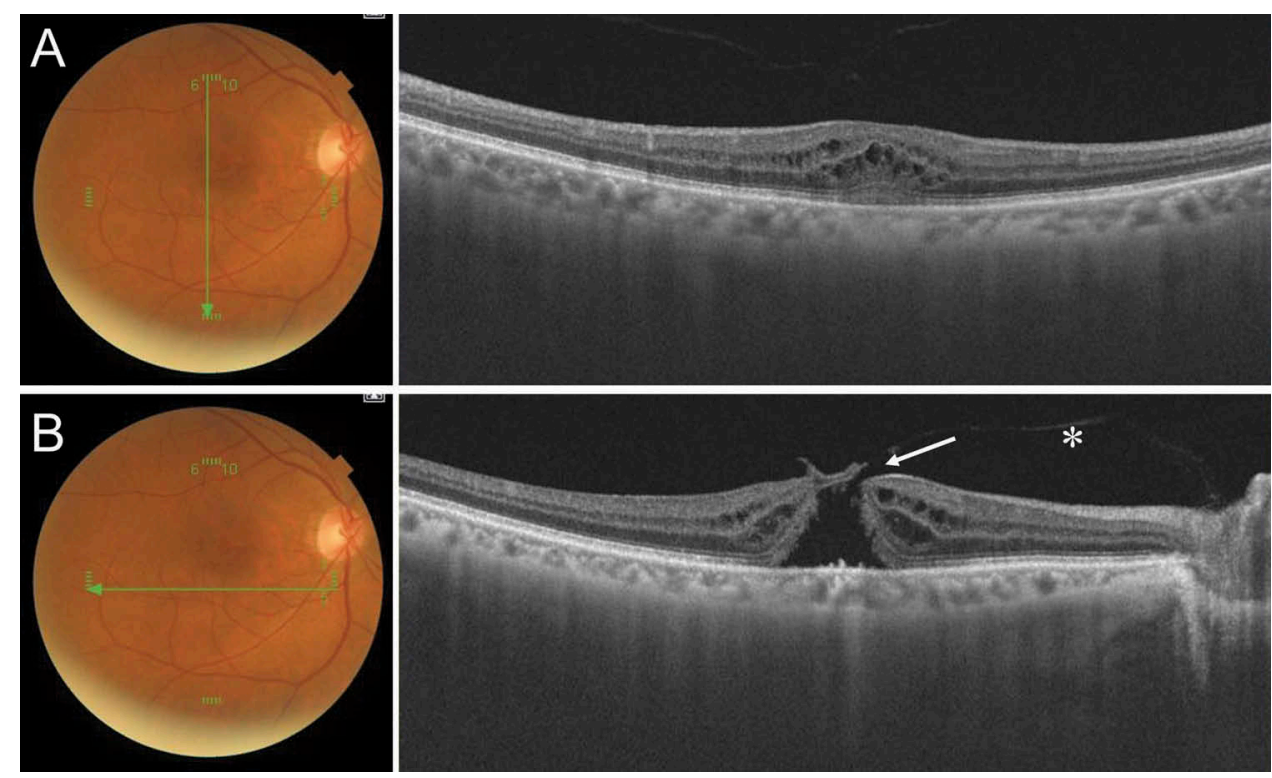

FIGURE 3. Imaging using spectral-domain optical coherence tomography (SD-OCT) of a patient with vitreomacular interface abnormalities. A vertical OCT scan passing through the macula shows presence of intraretinal cystoid spaces suggestive of cystoid macular edema (A). However, a horizontal OCT scan passing just inferior to the fovea (B) shows presence of abnormal vitreomacular traction (white asterisk) and retinal tissue defect (white arrow) suggestive of a full-thickness macular hole. The illustrative case shows the importance of evaluation of each OCT B-scan to be able to arrive at the correct diagnosis.

Knowledge of such agents helps in identifying patients at high risk, who can be screened periodically for the development of retinal disease. Long-term use of such agents may be associated with maculopathy that predominantly affects the outer retina including photoreceptors and vascular plexuses. Adverse events such as maculopathy are rare and usually develop after chronic, long-term use of drugs (usually many months later). Hence, clinical trials that evaluate safety and efficacy of novel therapeutic agents may not be powered to detect such adverse drug reactions. Often, ocular manifestations of patients on drug therapies may be confusing due to other comorbidities in the patient, which may lead the ophthalmologist to suspect infections and inflammatory pathologies leading to UME and maculopathy rather than toxicity due to the drug. ${ }^{73,74}$

Various drugs including antimalarial chloroquine and hydroxychloroquine, ${ }^{75}$ topiramate ${ }^{76}$ tacrolimus, ${ }^{77}$ antiviral agents such as ritonavir, ${ }^{78}$ tamoxifen, ${ }^{79}$ clofazimine $^{80} \quad$ sertraline $^{81}$ deferoxamine, ${ }^{82}$ clomiphene ${ }^{83}$ paclitaxel, ${ }^{84}$ BRAF inhibitors such as Vemurafenib (used in melanomas), ${ }^{85,86}$ and recently, antibiotics such as linezolid ${ }^{74}$ have been implicated in the development of maculopathy. Maculopathies due to these agents can present with intraretinal cystoid spaces or SRF accumulation (except chloroquine, hydroxychloroquine, and ritonavir). Usually, the presentation is symmetrical and bilateral (Figure 4). With increasing number of novel drugs introduced for various clinical indications, it is imperative to monitor long-term effects of these agents on critical tissues such as retinal photoreceptors, the damage to which may be irreversible.

Drug-induced maculopathies can be diagnosed using multimodal imaging techniques such as FA and OCT, which are able to effectively rule out infectious, inflammatory, and vascular pathologies leading to macular edema. Once drug toxicity is strongly suspected, the offending agents can be withdrawn or substituted. Reversal of retinal structural changes on OCT helps clinch the diagnosis of drug toxicity. However, with certain drugs such as chloroquine, hydroxychloroquine, and ritonavir, the structural changes may persist despite drug withdrawal. In addition, electrophysiological studies aid in the detection of photoreceptor and RPE damage due to drug intake. In cases with atypical retinal edema, and in non-responsive cases, electrophysiological studies help in assessing the structural damage to the RPE and photoreceptors.

\section{Pseudophakic and Postsurgical Macular Edema}

CME following cataract surgery, also known as IrvineGass syndrome, is a well-known cause of poor vision following uneventful cataract surgery. ${ }^{87-89}$ The incidence of clinical (symptomatic) pseudophakic cystoid macular edema (PCME) has been greatly reduced because of the advances in surgical techniques (approximately $0.1-2.3 \%$ ) including phacoemulsification and small-incision cataract surgery. ${ }^{87,90} \mathrm{~A}$ large 

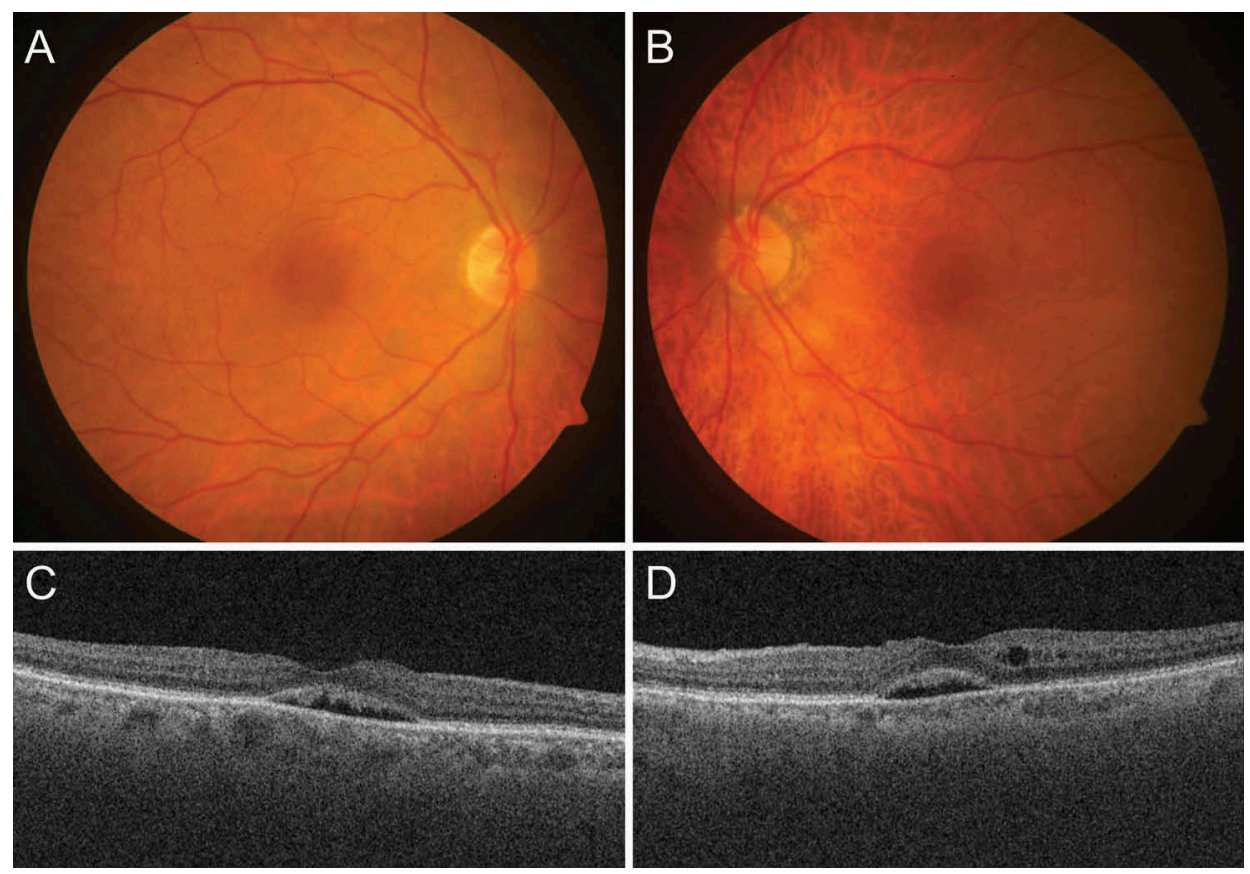

FIGURE 4. Fundus photographs of the right (A) and left eyes (B) of a 62-year-old female on chronic sertraline therapy (for the past 7 months) who presented with diminution of vision in both the eyes. Fundus examination revealed presence of a dull central foveal reflex. Spectral-domain optical coherence tomography (SD-OCT) scans of both the eyes (C and D) show presence of subretinal fluid in both the eyes and intraretinal cystoid spaces in the left eye. The patient was diagnosed with sertraline toxicity. The offending drug was withdrawn and the patient showed complete reversal of the maculopathy.

retrospective study including 81,984 eyes revealed that the incidence of PCME in eyes without operative complications, diabetes, or risk factors was $1.17 \% .{ }^{91}$ The incidence of clinically significant PCME peaks at approximately 5 (4-12) weeks in a healthy population.90 The condition is usually self-limiting, and the resolution of symptoms usually occurs within 3-12 months.

Although PCME can occur in healthy eyes with no surgical complications, risk factors increase the likelihood of it occurring. Patient factors predisposing to PCME include PCME in the contralateral eye, African-American origin, and any risk factor that may disrupt the blood-retinal barrier such as diabetes mellitus, uveitis, retinal vein occlusion, retinal degeneration, macular degeneration, radiation retinopathy, epiretinal membranes, choroidal tumors, prostaglandin analog use, and aging. ${ }^{87,91,92}$ Surgical factors include inflammation-inducing complications such as retained lens material, posterior capsule rupture, vitreous loss and vitreomacular traction, and excessive intraoperative manipulations such as mechanical pupil stretch or iris prolapse during surgery, the presence of an anterior chamber intraocular lens, filtering or other glaucoma operations, and intraocular surgeries. ${ }^{87}$

Conventionally, PCME is classified as angiographic (seen on FA) or clinical (associated with decreased visual acuity) and acute (within 6 months) or chronic (more than 6 months). ${ }^{93}$ However, OCT definitions for CME have been recently added and the incidence of PCME varies between $0.2 \%$ and $20 \%{ }^{94}$ depending on the definition used for diagnosis, which include clinical, angiographic, and tomographic. The incidence of CME measured by OCT is as high as $41 \% .{ }^{95}$ Antcliff et al. ${ }^{17}$ compared OCT with fundus FA for detecting PCME and found that the sensitivity was $96 \%$ and the specificity was $100 \%$ for OCT. Recently, many authors have reported microcystic edema (MME) in the central macula, characterized by isolated INL cystoid changes in the absence of outer plexiform alterations. ${ }^{96-98}$ The incidence, risk factors, and prophylactic response to topical nonsteroidal anti-inflammatory drugs (NSAIDs) by MME are very similar to those of CME. This suggests that MME is simply a mild form of PCME.

Sometimes, it is difficult to differentiate diabetic macular edema (DME) from PCME after cataract surgery in diabetic patients. However, in order to properly treat these eyes, it is crucial to define PCME appropriately. Pathogenesis of DME involves chronic hyperglycemia-induced oxidative stress, impaired blood flow, hypoxia, pericyte loss, endothelial cell loss, downregulation of glial cell-derived neurotrophic factor, and blood-retinal barrier dysfunction. On the other hand, PCME is induced by an acute and local release of inflammatory mediators during the surgery from lens epithelial cells and uveal tissue in the anterior segment. If mediators diffuse to the vitreous and retina, the inflammatory response will cause 
local vasodilatation and disruption of the blood-retinal barrier. Increased vascular permeability may lead to fluid accumulation in the inner nuclear and outer plexiform layers of the retina, and CME will develop. ${ }^{99}$

Munk et al. ${ }^{90}$ described OCT criteria to differentiate PCME from DME. A higher macular thickness/ retinal volume ratio, a thicker outer nuclear layer $(\mathrm{ONL}) / H e n l e$ 's layer, solely inner nuclear layer (INL) cysts, absence of epiretinal membrane, intact hyper-reflective outer retinal bands, and presence of SRF likely refer to PCME, whereas a higher ONL/INL thickness ratio parafoveally, the presence of microaneurysms, hard exudates, and microfoci, the presence of additional ganglion cell or retinal nerve fiber layer cysts, and the absence of SRF, mainly ONL cysts, and disruption of the photoreceptor layers are characteristic of DME. In contrast to the PCME eyes, the majority of DME eyes preserve foveal depression (Figure 5).

Disturbance of the inner blood-retinal barrier causes a secondary choroidal thickening. Several large-scale studies reported an increase in choroidal thickness following uneventful small incision cataract surgery, with maximal increase 1 month postoperatively. ${ }^{100-102}$ Moreover, choroidal thickness decreased in correlation with resolution of the edema.
However, even following PCME resolution, choroidal thickness remained significantly higher in the affected eyes compared to the fellow eyes. The finding of increased choroidal thickness in eyes with PCME may be explained by an alteration of the choroidal vessels walls secondary to the inflammatory state. This theory may be supported by reports describing choroidal changes observed with noninfectious uveitis such as VKH disease ${ }^{103,104}$ and Behçet's disease. ${ }^{105}$ In addition, in VKH disease, inflammatory thickening of the choroid (due to dense granulocytic infiltration) causes development of choroidal folds. These changes result in a delay in choriocapillaris and arterial filling, which can be observed on FA and indocyanine green angiography (ICGA). Secondary alterations occur in the RPE due to choroidal hypoperfusion leading to multiple pin-point leaks (characteristic of VKH disease), that slowly fill and lead to serous retinal detachment. ${ }^{106,107}$

The prevention of Irvine-Gass syndrome continues to pose challenges for ophthalmologists, due to its ability to affect individuals without any obvious predisposing factors at variable times of onset postoperatively. ${ }^{108}$ Some studies demonstrated negligible benefit with NSAID use after uncomplicated cataract surgery in patients without risk factors, ${ }^{88,109}$

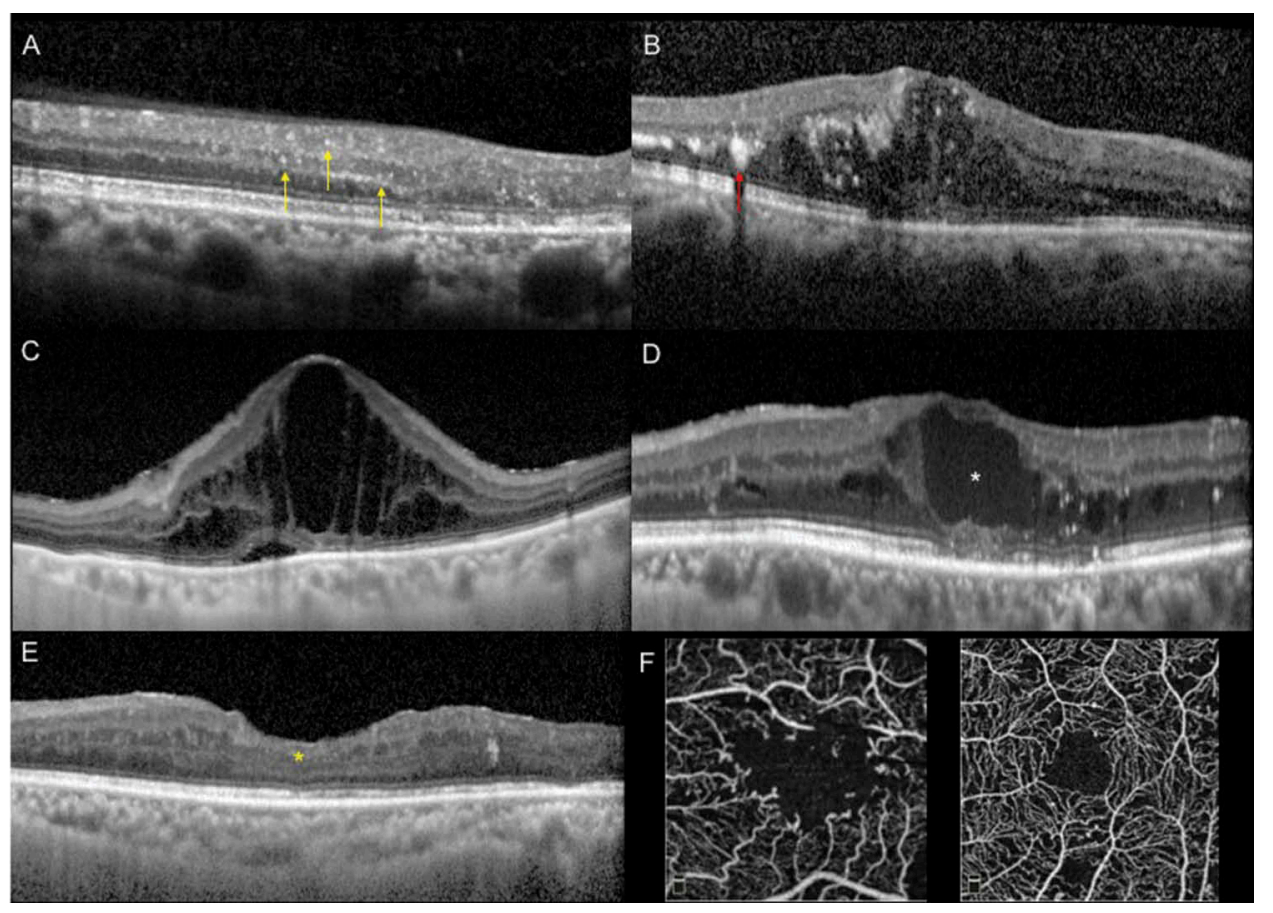

FIGURE 5. Various spectral-domain optical coherence tomography (SD-OCT) signs help distinguishing diabetic macular edema (DME) form other causes of cystoid macular edema (CME). One of the first biomarkers of inflammation in the diabetic retina is the intracellular swelling of the Muller cells, visible tomographically as hyperreflective retinal spots (A, yellow arrows), that can be distinguished from hyperreflective hard exudates (B, red arrow) that are bigger and cause back-shadowing. In early stages of DME, the appearance is 'spongiform' (B) and only later the cysts become well defined (C). With a progressive increase of the height of the cysts, a snapping of the axons of the bipolar cells can happen (D, white asterisk). This causes and interruption of the visual pathway from the photoreceptors to the nerve fibers, leading to a disorganization of the retinal inner layers (E, yellow asterisk) that accounts for a low visual acuity despite the absence of intraretinal fluid. A second input to the disorganization of the inner retinal layers may come from obliteration of foveal and perifoveal capillaries detected on optical coherence tomography angiography (OCTA) (F) . 
whereas others support their use in the treatment and prophylaxis of PCME in uncomplicated cases. In subjects undergoing cataract surgery, and at low risk for PCME, the routine use of preoperative nepafenac was suggested necessary only to achieve a faster visual recovery. ${ }^{110}$ However, prophylactic therapy should be considered in those with high risk like diabetic patients especially those with diabetic retinopathy due to the deficient blood-retinal barrier and advanced vascular changes. Options for prevention of macular edema after cataract surgery in patients with non-proliferative diabetic retinopathy include preoperative treatment with steroids, intravitreal injections of anti-VEGFs, laser treatment, and topical NSAIDs. It seems more prudent to prevent PCME rather than treat it, since treatment usually involves more invasive methods like intravitreal NSAID, ${ }^{111}$ subtenon triamcinolone, ${ }^{112}$ or intravitreal dexamethasone implant injections. Boscia et al. suggested that all diabetic patients undergoing cataract surgery should be treated with topical NSAIDs to prevent PCME. Intravitreal anti-VEGF drugs and steroids, combined with cataract surgery, may be considered in patients with preexisting DME. ${ }^{113}$

The beneficial effect of prednisolone acetate eye drops mono-therapy after cataract surgery has scarcely been demonstrated ${ }^{109,114}$; rather, its use has remained a legacy of practice for over 50 years. Corticosteroids are effective in suppressing postoperative inflammation, but have little suppression effect on PCME and potentially increase intraocular pressure. In several studies, almost all PCME cases occurred in spite of conventional postoperative topical steroid treatment including prednisolone or dexamethasone for 4-6 weeks. The problems with steroids are limited penetration and adverse effects with prolonged use like intraocular pressure spikes, delayed wound healing, and herpes virus activation. Due to anatomic membrane barriers and the lacrimal drainage, it can be difficult to obtain therapeutic drug concentrations in the posterior parts of the eye after topical administration. However, in a recent retrospective chart review of 1835 who underwent phacoemusification and received only post-operative topical prednisolone (721 patients) or topical dexamethasone (414 patients) with no NSAIDS addition, the rate of postoperative CME was, respectively, $4 \%$ and $4.1 \% .{ }^{115}$

It is postulated that surgical manipulation within the anterior chamber may lead to the release of arachidonic acid from uveal tissue, with the production of either leukotrienes via the lipoxygenase pathway or prostaglandins via the cyclooxygenase (COX) pathway. ${ }^{116}$ Subsequently, inflammatory mediators diffuse posteriorly into the vitreous and disrupt the blood-retinal barrier. This disruption results in increased permeability of the perifoveal capillaries and fluid accumulation within the retina. ${ }^{94}$
Treatment options correspond to many postulated mechanisms for the formation of PCME. Shelsta and Jampol $^{117}$ suggested a stepwise algorithm for PCME treatment. They recommended starting with the initial combination of a topical NSAID and a topical corticosteroid, either as monotherapy or combined therapy. The role of corticosteroids in the treatment of PCME involves the inhibition of leukotriene and prostaglandins synthesis. ${ }^{118}$ Corticosteroids decrease prostaglandins production by inhibiting phospholipase A2 in the arachidonic acid cascade. In addition to their antiinflammatory properties, corticosteroids also inhibit macrophage and neutrophil migration and decrease capillary permeability and vasodilation. ${ }^{119}$ NSAIDs work by inhibiting the COX enzymes. They are active in the inflammatory process, catalyzing the biosynthesis of eicosanoids from arachidonic acid to produce prostaglandins and thromboxanes. ${ }^{120}$ Prostaglandins within the eye produce vasodilatation and disruption of the blood-ocular barrier. ${ }^{120}$

For refractory cases, Benhamou et al. ${ }^{121}$ administered repeated intravitreal triamcinolone injections, while Bellocq et al. ${ }^{122}$ assessed the effectiveness of intravitreal dexamethasone implants (the EPISODIC study). They found that more than half of the patients who were followed-up for at least 1 year presented neither a functional nor an anatomical recurrence. Falavarjani et al. ${ }^{123}$ reviewed the use of intravitreal bevacizumab injection for the treatment of PCME. They did not find any high-quality evidence to recommend anti-vascular endothelial growth factor agents as a routine treatment for PCME. However, they concluded that bevacizumab injection can be considered in patients with refractory PCME that is unresponsive to intravitreal steroids.

\section{Diabetic Macular Edema}

DME is a major public health concern, representing the major cause of visual loss in individuals with diabetic retinopathy. The pathogenesis of DME is multifactorial and complex, but this downstream cascade of events is reflected into the SD-OCT biomarkers and appearances of DME that can help distinguish it from other causes of CME.

Chronic hyperglycemia induces overproduction of superoxide by the mitochondrial electron transport chain ${ }^{124}$ and this excess production of reactive oxygen species (ROS) can be the upstream event leading to DME. Evidences have demonstrated that nitric oxide produced by the ROS appears to have a predominant role in leukostasis. Increased leukostasis has been correlated with increased expression of intercellular adhesion molecule- 1 and vascular leakage ${ }^{125,126}$ that lead to a breakdown of the blood-retinal barrier. An altered blood-retinal barrier implies an increase in the 
inflammatory response, and the release of inflammatory cytokines causes an intracytoplasmic swelling of the Muller cells, the glial elements of the retina. This swelling causes a release of permeability disturbing substances from the Muller cells, such as VEGF. VEGF plays an important role in the alteration of vascular permeability and development of DME.

Swollen Muller cells are often the first SD-OCT biomarker in patients with diabetic retinopathy without $\mathrm{DME}$, and they appear as small, sometimes punctiform, reflective lesions, visible on SD-OCT in both inner retina and outer retina (hyperreflective retinal spots, HRS). Coscas et al. ${ }^{127}$ were the first to describe small, punctiform hyper-reflective elements, scattered throughout all retina layers, but mostly in the outer retina, in agerelated macular degeneration (AMD). These authors interpreted HRS as activated microglial cells in latestage AMD. Lad et al. documented microglia involvement by immunohistochemistry in human autopsy eyes with late-stage AMD (geographic atrophy and choroidal neovascularization). Madeira et al. ${ }^{128}$ reported microglial activation in different retinal degenerative diseases (including diabetic retinopathy) contributing to chronic neuro-inflammation, with release of proinflammatory mediators (by activated microglial cells) and increased oxidative stress. ${ }^{128,129}$ These activated microglial cells could be visualized in the retina as HRS, by SD-OCT. ${ }^{127,130,131}$ Vujosevic et al. ${ }^{130}$ reported the increase in HRS in diabetic patients versus normal subjects (even in diabetic eyes without any clinical sign of retinopathy), suggesting that HRS may represent aggregates of activated microglial cells that migrate, with the progressing of the disease, confirming previous histopathologic findings. These HRS are quite unique of AMD and DME and have been rarely described in UME.

HRS that may represent swollen Muller cells can be distinguished from hard exudates since the latter have a larger size $(>30 \mathrm{~mm})$, higher reflectivity (similar to RPE-Bruch complex), and with back shadowing.

From intraretinal edema of the Muller cells, continuous inflammation and the breakdown of the bloodretinal barrier lead to extracellular edema and frank DME. SD-OCT images of DME depict the presence of low intraretinal reflectivity, due to fluid accumulation in the extracellular space of the retina. The process begins as increased thickening with sponge-like appearance of retinal layers and later advancing to the typical image of cystoid spaces.

When there is a situation of breakdown of the blood-retinal barrier, the Starling law governing the movements of fluid applies. ${ }^{132}$ Any change in the equilibrium between hydrostatic, oncotic, and osmotic pressure gradients across the retinal vessels contributes to further water movements and may result in increased edema formation. An increase in $\mathrm{P}_{\text {plasma }}$ (hydrostatic pressure) due to increased systemic blood pressure does contribute to retinal edema formation when there is a breakdown of the blood-retinal barrier. A decrease in $\mathrm{P}_{\text {tissue }}$ (osmotic pressure) is also an important component: any alteration in the cohesion of the retinal tissue due to pathologies, such as vitreous traction with pulling on the inner limiting membrane of the retina will lead to a decrease in $\mathrm{P}_{\text {tissue }}$ thus facilitating fluid accumulation in the retina. Extravagation of proteins and lipoproteins, such as in hard exudates, increase the oncotic pressure in the retinal tissue and draw more water in the retinal extracellular space contributing to a progressive increase in retinal edema.

In larger intraretinal cysts, the tissue that connects the retinal photoreceptors to the ganglion cells consists mainly of bipolar cells. Pelosini et al. ${ }^{133}$ suggested that if edema increases retinal thickness beyond an elastic limit, bipolar axons can snap and cause loss of visual information signaling from photoreceptors to ganglion cells. This bipolar destruction may not be completely reversible, accounting for disorganization of retinal inner layers (DRIL) on SD-OCT. ${ }^{134}$ DRIL is a novel OCT parameter characterized by the inability to distinguish boundaries between inner layers on SD-OCT that may have an effect on the visual outcomes of patients with DME.

More than $55 \%$ of patients with diabetes with macular edema and about $70 \%$ of those with clinically significant macular edema have simultaneous macular ischemia. ${ }^{135}$ Both capillary non-perfusion and capillary closure are the result of retinal microthombosis. Increased platelet adhesiveness and aggregation in DME seem to be secondary to alteration in endothelial integrity and increase in inflammatory cytokines.

OCT angiography (OCTA), a novel non-invasive dye-less technique of angiographic imaging of the retina and choroid, can detect microcirculation impairment in the macula even before clinically apparent retinopathy develops. In eyes with DME and diabetic retinopathy, OCTA seems to better delineate the foveal avascular zone and areas of flow impairment when compared with FA. Spaide ${ }^{136}$ described flow voids in the deep vascular plexus that were topographically associated with the cystoid spaces. Flow voids were also seen in the superficial plexus but to a lesser extent. Similarly, microaneuryms were found in both plexuses but more frequently in the deep vascular plexus. Many of these microaneurysms were adjacent to the cystoid spaces, suggesting that the major contributors to DME are the microaneurysms in the deep capillary plexus. Macular ischemia may be a cause of visual acuity loss and it has been suggested that DRIL is strongly correlated 
with non-perfusion areas. ${ }^{134}$ Because there is some evidence showing that retinal vessels can re-perfuse after the resolution of DME, OCTA imaging of patients with DRIL may help to identify a threshold for capillary loss that will result in DRIL and poor visual outcome.

\section{Vascular Macular Edema}

A number of clinical entities can lead to development of choroidal ischemia, such as systemic hypertension, pregnancy-induced hypertension, pre-eclampsia, and vasculitic causes such as giant cell arteritis, among others. These patients may have normal retinal circulation and a normal-looking fundus, but deficits in the choroidal perfusion which may be detectable only using FA. Such causes of choroidal ischemia, though rare, may be associated with serous retinal detachment and accumulation of SRF, mimicking UME. The mechanism of development of serous retinal detachment may be related to the dysfunction and disturbance of the RPE function due to lack of choroidal perfusion. ${ }^{137}$

Conditions associated with significantly thickened choroid, such as VKH disease, may also demonstrate choroidal hypoperfusion. In a study by Fardeau et al., FA, ICGA, and OCT characteristics of patients with VKH disease were performed at various stages of the disease. A total of 13 patients with early active disease had bilateral serous retinal detachment. The authors observed choriocapillaris filling delay in all 13 patients, and arterial filling delay on ICGA in 10 patients, and decreased choroidal vessels in 9 patients. Thus, the authors concluded that choroidal hypoperfusion due to significantly thickened choroid resulted in dye leakage through the abnormal RPE cells into the subretinal space caused by ischemic damage. ${ }^{106}$ Thus, generalized abnormalities of the choroidal vasculature may be rare associated with serous retinal detachments similar to UME.

\section{Tumoral Macular Edema}

Certain intraocular tumors may be rarely associated with retinal edema, macular thicknening, and accumulation of serous SRF. The mechanism of development of macular edema could be immune-mediated inflammatory changes at the macula, or due to deposition of tumor cells leading to local changes in the milieu such as alterations in the oncotic pressure, causing fluid accumulation. Precise mechanisms of development of retinal edema are, however, still not precisely known. Although rare, macular edema may develop in such conditions, and early diagnosis is only possible if a differential diagnosis is considered and high clinical suspicion is maintained.

Intraocular lymphomas are important causes of masquerades because they can present with protean manifestations, such as vitritis, retinal vasculitis, hypopyon uveitis, or even macular edema. ${ }^{138-140}$ Fardeau et al. compared the clinical, angiographic, and tomographic characteristics of 244 consecutive patients with severe posterior uveitis who underwent vitreous biopsy for cytological analysis. The authors obtained 53 positive samples for intraocular lymphoma (non-Hodgkin's type) and 191 without any tumor cells. While macular edema was less common among subjects with nonHodgkin's lymphoma compared to patients without intraocular tumor $(11.3 \%$ versus $19.9 \%)$, the $p$ value was not significant $(p=0.217) .^{58}$ Thus, among patients with macular edema, and especially those with nodular hyper-reflective lesions in the RPE, intraocular lymphoma should be considered.

Deposition of tumor cells and resultant local changes may also lead to accumulation of fluid in the macula, simulating UME. For instance, Kim et al. reported a case of acute lymphoblastic leukemia in a 45-year-old woman which presented with bilateral serous retinal detachments leading to central scotoma in both the eyes, but no systemic manifestations. The authors postulated that serous retinal detachment in these patients may occur due to choroidal involvement by leukemic cells causing dysfunction of the RPE and breakdown of the bloodretinal barrier. ${ }^{141}$ In another case by Izzedine et al, bilateral serous retinal detachment in a 48-year-old male led to the diagnosis of nephrotic syndrome. Further study of the renal biopsy revealed the presence of amyloid light chain deposits. ${ }^{142}$

\section{CONCLUSIONS AND SUMMARY}

A number of uveitic and non-uveitic entities may result in development of macular edema due to activation of various pro-inflammatory pathways and breakdown of blood-retinal barrier. UME can occur as a complication or an associated feature of all forms of uveitis including AU and retinal vasculitis. In addition, various non-uveitic entities such as diabetes, vein occlusions, postoperative (following cataract surgery), and drug intake may be associated with development of macular edema. It is imperative to obtain a detailed medical and surgical history, and perform a detailed ophthalmic evaluation to determine the cause of UME. Imaging modalities such as FA and OCT are very useful in identifying the cause and extent of the pathology. Thus, various possibilities and differential diagnosis must be kept in mind during the assessment of patients with UME.

\section{DECLARATION OF INTEREST}

The authors report no conflicts of interest. The authors alone are responsible for the content and writing of the paper. 


\section{ORCID}

Aniruddha Agarwal (1) http://orcid.org/0000-00034985-9855

Alessandro Invernizzi (1) http://orcid.org/0000-00033400-1987

\section{REFERENCES}

1. Fardeau C, Champion E, Massamba N, LeHoang $P$. Uveitic macular edema. Eye Lond Engl. 2016;30(10):12771292. doi:10.1038/eye.2016.115.

2. Thurau SR. [Cystoid macular edema in uveitis]. Ophthalmol Z Dtsch Ophthalmol Ges. 2005;102(5):485-490. doi:10.1007/s00347-005-1183-9.

3. de Smet MD, Okada AA. Cystoid macular edema in uveitis. Dev Ophthalmol. 2010;47:136-147. doi:10.1159/ 000320077.

4. Cunha-Vaz J, Coscas G. Diagnosis of macular edema. Ophthalmol I Int Ophtalmol Int J Ophthalmol Z Augenheilkd. 2010;224(Suppl 1):2-7. doi:10.1159/ 000315156.

5. Gupta V, Al-Dhibi HA, Arevalo JF. Retinal imaging in uveitis. Saudi J Ophthalmol Off J Saudi Ophthalmol Soc. 2014;28(2):95-103. doi:10.1016/j.sjopt.2014.02.008.

6. Bazvand F, Zarei M, Ebrahimiadib N, et al. Ocular manifestations, conventional fundus fluorescein angiographic findings, and relationship between angiographic findings and visual acuity in Behçet's disease. Semin Ophthalmol. 2017;32(6):764-771.doi:10.1080/08820538.2016.1178310.

7. Kim M, Kwon HJ, Choi EY, Kim SS, Koh HJ, Lee SC. Correlation between fluorescein angiographic findings and visual acuity in Behçet retinal vasculitis. Yonsei Med J. 2015;56(4):1087-1096. doi:10.3349/ymj.2015.56. 4.1087.

8. Thomas AS, Redd T, Campbell JP, et al. The impact and implication of peripheral vascular leakage on ultra-widefield fluorescein angiography in uveitis. Ocul Immunol Inflamm. October 2017;1-7. doi:10.1080/ 09273948.2017.1367406.

9. Karampelas M, Sim DA, Chu C, et al. Quantitative analysis of peripheral vasculitis, ischemia, and vascular leakage in uveitis using ultra-widefield fluorescein angiography. Am J Ophthalmol. 2015;159(6):1161-1168.e1. doi:10.1016/j.ajo.2015.02.009.

10. Mesquida M, Llorenç V, Fontenla JR, Navarro MJ, Adán A. Use of ultra-wide-field retinal imaging in the management of active Behçet retinal vasculitis. Retina Phila Pa. 2014;34(10):2121-2127.

doi:10.1097/ IAE.0000000000000197.

11. Chi Y, Guo C, Peng Y, Qiao L, Yang L. A prospective, observational study on the application of ultra-wide-field angiography in the evaluation and management of patients with anterior uveitis. PloS One. 2015;10(3): e0122749. doi:10.1371/journal.pone.0122749.

12. Campbell JP, Leder HA, Sepah YJ, et al. Wide-field retinal imaging in the management of noninfectious posterior uveitis. Am J Ophthalmol. 2012;154(5):908-911.e2. doi:10.1016/j.ajo.2012.05.019.

13. Markomichelakis NN, Halkiadakis I, Pantelia E, et al. Patterns of macular edema in patients with uveitis: qualitative and quantitative assessment using optical coherence tomography. Ophthalmology. 2004;111(5):946-953. doi:10.1016/j.ophtha.2003.08.037.

14. Grewal DS, O'Sullivan ML, Kron M, Jaffe GJ. Association of disorganization of retinal inner layers with visual acuity in eyes with uveitic cystoid macular edema. Am J Ophthalmol. 2017;177:116-125. doi:10.1016/j.ajo.2017. 02.017.

15. Roesel M, Henschel A, Heinz C, Dietzel M, Spital G, Heiligenhaus A. Fundus autofluorescence and spectral domain optical coherence tomography in uveitic macular edema. Graefes Arch Clin Exp Ophthalmol Albrecht Von Graefes Arch Klin Exp Ophthalmol. 2009;247(12): 1685-1689. doi:10.1007/s00417-009-1149-8.

16. Tran THC, de Smet MD, Bodaghi B, Fardeau C, Cassoux N, Lehoang P. Uveitic macular oedema: correlation between optical coherence tomography patterns with visual acuity and fluorescein angiography. $\mathrm{Br} J$ Ophthalmol. 2008;92(7):922-927. doi:10.1136/ bjo.2007.136846.

17. Antcliff RJ, Stanford MR, Chauhan DS, et al. Comparison between optical coherence tomography and fundus fluorescein angiography for the detection of cystoid macular edema in patients with uveitis. Ophthalmology. 2000;107(3):593-599.

18. Mitkova-Hristova VT, Konareva-Kostianeva MI, Balian AM, Stoyanova NS, Semerdzhieva MA. Discrepancies between spectral domain optical coherence tomography and fluorescein angiography in detecting uveitic macular edema. Folia Med (Plovdiv). 2015;57(3-4):207-215. doi:10.1515/folmed-2015-0040.

19. Jabs DA, Nussenblatt RB, Rosenbaum JT. Standardization of uveitis nomenclature (sun) working group. standardization of uveitis nomenclature for reporting clinical data. Results of the first international workshop. Am J Ophthalmol. 2005;140:509-516.

20. Chang JH, McCluskey PJ, Wakefield D. Acute anterior uveitis and HLA-B27. Surv Ophthalmol. 2005;50(4):364-388. doi:10.1016/j.survophthal.2005. 04.003.

21. D'Ambrosio EM, La Cava M, Tortorella P, Gharbiya M, Campanella M, Iannetti L. Clinical features and complications of the HLA-B27-associated acute anterior uveitis: a Metanalysis. Semin Ophthalmol. 2017;32(6):689-701. doi:10.3109/08820538.2016.1170158.

22. Chee S-P, Bacsal K, Jap A, S-Y S-T, Cheng CL, Tan BH. Clinical features of cytomegalovirus anterior uveitis in immunocompetent patients. Am J Ophthalmol. 2008;145 (5):834-840. doi:10.1016/j.ajo.2007.12.015.

23. Tugal-Tutkun I, Otük-Yasar B, Altinkurt E. Clinical features and prognosis of herpetic anterior uveitis: a retrospective study of 111 cases. Int Ophthalmol. 2010;30 (5):559-565. doi:10.1007/s10792-010-9394-8.

24. Al-Mansour YS, Al-Rajhi AA, Al-Dhibi H, Abu El-Asrar AM. Clinical features and prognostic factors in Fuchs' uveitis. Int Ophthalmol. 2010;30(5):501-509. doi:10.1007/ s10792-010-9379-7.

25. M-L B, Kim SJ, Thorne JE, et al. Incidence of cystoid macular edema after cataract surgery in patients with and without uveitis using optical coherence tomography. Am J Ophthalmol. 2009;148(1):128-135.e2.doi:10.1016/j. ajo.2009.02.029.

26. Llop SM, Papaliodis GN. Cataract Surgery complications in uveitis patients: A review article. Semin Ophthalmol. 2018;33(1):64-69. doi:10.1080/08820538.2017.1353815.

27. Okhravi N, Lightman S. Cystoid macular edema in uveitis. Ocul Immunol Inflamm. 2003;11:29-38.

28. Kotaniemi K, Penttila H. Intraocular lens implantation in patients with juvenile idiopathic arthritis-associated uveitis. Ophthalmic Res. 2006;38(6):318-323. doi:10.1159/ 000096225.

29. Bonfioli AA, Damico FM, Curi ALL, Orefice F. Intermediate uveitis. Semin Ophthalmol. 2005;20(3):147154. doi:10.1080/08820530500232035. 
30. Babu BM, Rathinam SR. Intermediate uveitis. Indian J Ophthalmol. 2010;58(1):21-27. doi:10.4103/0301-4738. 58469.

31. Paović J, Paović P, Vukosavljević M. Clinical and immunological features of retinal vasculitis in systemic diseases. Vojnosanit Pregl. 2009;66:961-965.

32. Androudi S, Dastiridou A, Symeonidis C, et al. Retinal vasculitis in rheumatic diseases: an unseen burden. Clin Rheumatol. 2013;32(1):7-13.doi:10.1007/s10067-012-2078-1.

33. Rosenbaum JT, Sibley CH, Lin P. Retinal vasculitis. Curr Opin Rheumatol. 2016;28(3):228-235. doi:10.1097/ BOR.0000000000000271.

34. Agarwal A, Karkhur S, Aggarwal K, et al. Epidemiology and clinical features of inflammatory retinal vascular occlusions: pooled data from two tertiary-referral institutions. Clin Experiment Ophthalmol. 2018;46(1):62-74. doi:10.1111/ceo.12997.

35. Mir TA, Reddy AK, Burkholder BM. et al. Clinical features and incidence rates of ocular complications in patients with retinal vasculitis. Am J Ophthalmol. 2017;179:171-178. doi:10.1016/j.ajo.2017.05.007.

36. Agarwal A, Afridi R, Agrawal R, Do DV, Gupta V, Nguyen QD. Multimodal imaging in retinal vasculitis. Ocul Immunol Inflamm. 2017;25(3):424-433. doi:10.1080/ 09273948.2017.1319494.

37. Agarwal A, Handa S, Aggarwal K, et al. The role of dexamethasone implant in the management of tubercular uveitis. Ocul Immunol Inflamm. November 2017;1-9. doi:10.1080/09273948.2017.1400074.

38. Gunasekeran DV, Agrawal R, Agarwal A, et al. the collaborative ocular tuberculosis study (cots)-1: a multinational review of 251 patients with tubercular retinal vasculitis. Retina Phila Pa. April 2018. doi:10.1097/ IAE.0000000000002194.

39. Kaçmaz RO, Kempen JH, Newcomb C, et al. Ocular inflammation in Behçet disease: incidence of ocular complications and of loss of visual acuity. Am J Ophthalmol. 2008;146(6):828-836.doi:10.1016/j.ajo.2008.06.019.

40. Knickelbein JE, Tucker W, Kodati S, Akanda M, Sen HN. Non-invasive method of monitoring retinal vasculitis in patients with birdshot chorioretinopathy using optical coherence tomography. $\mathrm{Br}$ J Ophthalmol. August 2017. doi:10.1136/bjophthalmol-2016-309837.

41. Bonfioli AA, Sarcoidosis OF. Semin Ophthalmol. 2005;20 (3):177-182. doi:10.1080/08820530500231938.

42. Jovanović SV, Jovanović ZD, Radotić FM, Srećković SB, Paunović SS, Stojanović JD. Clinical aspects of posterior uveitis in ocular sarcoidosis. Acta Clin Croat. 2012;51: 247-253.

43. Sudharshan S, Ganesh SK, Biswas J. Current approach in the diagnosis and management of posterior uveitis. Indian J Ophthalmol. 2010;58(1):29-43. doi:10.4103/03014738.58470 .

44. Maenz M, Schlüter D, Liesenfeld O, Schares G, Gross U, Pleyer U. Ocular toxoplasmosis past, present and new aspects of an old disease. Prog Retin Eye Res. 2014;39: 77-106. doi:10.1016/j.preteyeres.2013.12.005.

45. Shah KH, Levinson RD, Yu F, et al. Birdshot chorioretinopathy. Surv Ophthalmol. 2005;50(6):519-541. doi:10.1016/j.survophthal.2005.08.004.

46. Davis JL. Ocular syphilis. Curr Opin Ophthalmol. 2014; 25(6):513-518. doi:10.1097/ICU.0000000000000099.

47. Gupta V, Gupta A, Rao NA. Intraocular tuberculosis - an update. Surv Ophthalmol. 2007;52(6):561-587. doi:10.1016/ j.survophthal.2007.08.015.

48. Damico FM, Kiss S, Young LH. Vogt-Koyanagi-Harada disease. Semin Ophthalmol. 2005;20(3):183-190. doi:10.1080/08820530500232126.
49. Spaide RF, Goldberg N, Freund KB. Redefining multifocal choroiditis and panuveitis and punctate inner choroidopathy through multimodal imaging. Retina Phila Pa. 2013;33(7):1315-1324. doi:10.1097/IAE.0b013e318286cc77.

50. Nazari Khanamiri H, Rao NA. Serpiginous choroiditis and infectious multifocal serpiginoid choroiditis. Surv Ophthalmol. 2013;58(3):203-232. doi:10.1016/j. survophthal.2012.08.008.

51. Ahnood D, Madhusudhan S, Tsaloumas MD, Waheed NK, Keane PA, Denniston AK. Punctate inner choroidopathy: a review. Surv Ophthalmol. 2017; 62(2):113-126. doi:10.1016/j.survophthal.2016.10.003.

52. Cornish KS, Williams GJ, Gavin MP, Imrie FR. Visual and optical coherence tomography outcomes of intravitreal bevacizumab and ranibizumab in inflammatory choroidal neovascularization secondary to punctate inner choroidopathy. Eur J Ophthalmol. 2011;21(4): 440-445. doi:10.5301/EJO.2010.6117.

53. Invernizzi A, Agarwal AK, Ravera V, et al. Comparing optical coherence tomography findings in different aetiologies of infectious necrotising retinitis. $\mathrm{Br} J$ Ophthalmol. 2018;102(4):433-437.doi:10.1136/bjophthalmol-2017-310210.

54. Invernizzi A, Agarwal A, Ravera V, Oldani M, Staurenghi G, Viola F. Optical coherence tomography findings in cytomegalovirus retinitis: a longitudinal study. Retina Phila Pa. 2018;38(1):108-117. doi:10.1097/ IAE.0000000000001503.

55. Neri P, Lettieri M, Fortuna C, Manoni M, Giovannini A. Inflammatory choroidal neovascularization. Middle East Afr J Ophthalmol. 2009;16(4):245-251. doi:10.4103/09749233.58422.

56. D'Ambrosio E, Tortorella P, Iannetti L. Management of uveitis-related choroidal neovascularization: from the pathogenesis to the therapy. J Ophthalmol. 2014;2014:450428. doi:10.1155/2014/450428.

57. Tugal-Tutkun I, Gupta V, Cunningham ET. Differential diagnosis of behçet uveitis. Ocul Immunol Inflamm. 2013;21(5):337-350. doi:10.3109/09273948.2013.795228.

58. Fardeau C, Lee CPL, Merle-Béral H, et al. Retinal fluorescein, indocyanine green angiography, and optic coherence tomography in non-Hodgkin primary intraocular lymphoma. Am J Ophthalmol. 2009;147(5):886-894. 894e1. doi:10.1016/j.ajo.2008.12.025.

59. Sims J. Scleritis: presentations, disease associations and management. Postgrad Med J. 2012;88(1046):713-718. doi:10.1136/postgradmedj-2011-130282.

60. Akpek EK, Thorne JE, Qazi FA, Do DV, Jabs DA. Evaluation of patients with scleritis for systemic disease. Ophthalmology. 2004;111(3):501-506. doi:10.1016/j. ophtha.2003.06.006.

61. Bernauer W, Pleisch B, Brunner M. Five-year outcome in immune-mediated scleritis. Graefes Arch Clin Exp Ophthalmol Albrecht Von Graefes Arch Klin Exp Ophthalmol. 2014;252(9):1477-1481. doi:10.1007/s00417014-2696-1.

62. Pavesio CE, Meier FM. Systemic disorders associated with episcleritis and scleritis. Curr Opin Ophthalmol. 2001;12:471-478.

63. Bainbridge J, Herbert E, Gregor Z. Macular holes: vitreoretinal relationships and surgical approaches. Eye Lond Engl. 2008;22(10):1301-1309. doi:10.1038/eye.2008.23.

64. Oh H. Idiopathic macular hole. Dev Ophthalmol. 2014;54:150-158. doi:10.1159/000360461.

65. Ip MS, Baker BJ, Duker JS, et al. Anatomical outcomes of surgery for idiopathic macular hole as determined by optical coherence tomography. Arch Ophthalmol Chic Ill 1960. 2002;120(1):29-35. 
66. Smiddy WE, Flynn HW. Pathogenesis of macular holes and therapeutic implications. Am J Ophthalmol. 2004;137 (3):525-537. doi:10.1016/j.ajo.2003.12.011.

67. Ac H, Dr G, Sl F. Macular hole. Surv Ophthalmol. 1998;42:393-416.

68. Di Antonio L, Toto L, Carpineto P, Mastropasqua A, De Nicola C, Mastropasqua L. Macular pseudohole development after sustained-release dexamethasone intravitreal implant for macular edema due to central retinal vein occlusion. Eur J Ophthalmol. 2014;24(1):134-137. doi:10.5301/ejo.5000317.

69. Lecleire-Collet A, Offret O, Gaucher D, Audren F, Haouchine B, Massin P. Full-thickness macular hole in a patient with diabetic cystoid macular oedema treated by intravitreal triamcinolone injections. Acta Ophthalmol Scand. 2007;85(7):795-798. doi:10.1111/j.1600-0420.2007 .00925.x.

70. Unoki N, Nishijima K, Kita M, et al. Lamellar macular hole formation in patients with diabetic cystoid macular edema. Retina Phila Pa. 2009;29(8):1128-1133.doi:10.1097/ IAE.0b013e3181a4d2d9.

71. De Benedetto U, Battaglia Parodi M, Knutsson KA, Lattanzio R, Bandello F, Iacono P. Macular hole after injection of dexamethasone intravitreal implant for macular oedema due to central retinal vein occlusion. Acta Ophthalmol (Copenh). 2013;91(1):e75-77. doi:10.1111/j.1755-3768.2012.02484.x.

72. Erdurman FC, Pellumbi A, Durukan AH. Lamellar macular hole formation in a patient with diabetic CME treated by intravitreal bevacizumab injections. Ophthalmic Surg Lasers Imaging Off J Int Soc Imaging Eye. 2012;43 Online: e87-89. doi:10.3928/15428877-20120823-05.

73. Kempen JH. Drug-induced maculopathy. Int Ophthalmol Clin. 1999;39:67-82.

74. Li J, Tripathi RC, Tripathi BJ. Drug-induced ocular disorders. Drug Saf. 2008;31:127-141.

75. Halfeld Furtado de Mendonça R, Maia OO, Yukihiko Takahashi W. Electrophysiologic findings in chloroquine maculopathy. Doc Ophthalmol Adv Ophthalmol. 2007;115(2):117-119. doi:10.1007/s10633007-9060-2.

76. Gualtieri W, Janula J. Topiramate maculopathy. Int Ophthalmol. 2013;33(1):103-106. doi:10.1007/s10792-0129640-3.

77. Koh T, Baek S-H, Han JI, Kim US. Maculopathy associated with tacrolimus (FK 506). Korean J Ophthalmol KJO. 2011;25(1):69-71. doi:10.3341/kjo.2011.25.1.69.

78. Pinto R, Vila-Franca M, Oliveira Afonso C, Ornelas C, Santos L. Ritonavir and bull's eye maculopathy: case report. GMS Ophthalmol Cases. 2013;3. doi:10.3205/ oc000011.

79. Doshi RR, Fortun JA, Kim BT, Dubovy SR, Rosenfeld PJ. Pseudocystic foveal cavitation in tamoxifen retinopathy. Am J Ophthalmol. 2014;157(6):1291-1298.e3. doi:10.1016/j. ajo.2014.02.046.

80. Kasturi N, Srinivasan R. Clofazimine-induced premaculopathy in a vitiliginous patient. J Pharmacol Pharmacother. 2016;7(3):149-151. doi:10.4103/0976-500X.189685.

81. Mason JO, Patel SA. Bull'S eye maculopathy in a patient taking sertraline. Retin Cases Brief Rep. 2015;9(2):131-133. doi:10.1097/ICB.0000000000000115.

82. Gelman R, Kiss S, Tsang SH. Multimodal imaging in a case of deferoxamine-induced maculopathy. Retin Cases Brief Rep. 2014;8(4):306-309. doi:10.1097/ICB.00000 00000000059.

83. Tunc M. Maculopathy following extended usage of clomiphene citrate. Eye Lond Engl. 2014;28(9):1144-1146. doi:10.1038/eye.2014.121.
84. Joshi MM, Garretson BR. Paclitaxel maculopathy. Arch Ophthalmol Chic Ill 1960. 2007;125(5):709-710. doi:10.1001/archopht.125.5.709.

85. Fonollosa A, Mesquida M, Adan A. Uveitic macular oedema after treatment with vemurafenib. Acta Ophthalmol (Copenh). 2015;93(8):e686-687. doi:10.1111/ aos.12678.

86. Choe CH, McArthur GA, Caro I, Kempen JH, Amaravadi RK. Ocular toxicity in BRAF mutant cutaneous melanoma patients treated with vemurafenib. $A m$ J Ophthalmol. 2014;158(4):831-837.e2. doi:10.1016/j. ajo.2014.07.003.

87. Shields MK, Adler PA, Fuzzard DRW, Chalasani R, Teong JMY A. Case of acute bilateral Irvine-Gass syndrome following uncomplicated phacoemulsification, demonstrated with optical coherence tomography. Case Rep Ophthalmol. 2015;6(1):143-148. doi:10.1159/ 000430087.

88. Singh R, Alpern L, Jaffe GJ. et al. Evaluation of nepafenac in prevention of macular edema following cataract surgery in patients with diabetic retinopathy. Clin Ophthalmol Auckl NZ. 2012;6:1259-1269. doi:10.2147/ OPTH.S31902.

89. Irvine SR. A newly defined vitreous syndrome following cataract surgery. Am J Ophthalmol. 1953;36:599-619.

90. Munk MR, Jampol LM, Simader C, et al. Differentiation of diabetic macular edema from pseudophakic cystoid macular edema by spectral-domain optical coherence tomography. Invest Ophthalmol Vis Sci. 2015;56(11): 6724-6733.doi:10.1167/iovs.15-17042.

91. McCafferty S, Harris A, Kew C, et al. Pseudophakic cystoid macular edema prevention and risk factors; prospective study with adjunctive once daily topical nepafenac $0.3 \%$ versus placebo. BMC Ophthalmol. 2017;17(1):16. doi:10.1186/s12886-017-0405-7.

92. Medić A, Jukić T, Matas A, Vukojević K, Sapunar A, Znaor L. Effect of preoperative topical diclofenac on intraocular interleukin-12 concentration and macular edema after cataract surgery in patients with diabetic retinopathy: a randomized controlled trial. Croat Med J. 2017;58:49-55.

93. Kim SJ, Belair M-L, Bressler NM, et al. A method of reporting macular edema after cataract surgery using optical coherence tomography. Retina Phila Pa. 2008;28(6):870-876.doi:10.1097/IAE.0b013e318169d04e.

94. Flach AJ. The incidence, pathogenesis and treatment of cystoid macular edema following cataract surgery. Trans Am Ophthalmol Soc. 1998;96:557-634.

95. Lobo CL, Faria PM, Soares MA, Bernardes RC, CunhaVaz JG. Macular alterations after small-incision cataract surgery. J Cataract Refract Surg. 2004;30(4):752-760. doi:10.1016/S0886-3350(03)00582-0.

96. Sotirchos ES, Saidha S, Byraiah G, et al. In vivo identification of morphologic retinal abnormalities in neuromyelitis optica. Neurology. 2013;80(15):1406-1414.doi:10.1212/ WNL.0b013e31828c2f7a.

97. Balk LJ, Killestein J, Polman CH, Uitdehaag BMJ, Petzold A. Microcystic macular oedema confirmed, but not specific for multiple sclerosis. Brain J Neurol. 2012;135(Pt12): e226. doi:10.1093/brain/aws216.authorreplye227.

98. Sigler EJ, Randolph JC, Charles S. Delayed onset inner nuclear layer cystic changes following internal limiting membrane removal for epimacular membrane. Graefes Arch Clin Exp Ophthalmol Albrecht Von Graefes Arch Klin Exp Ophthalmol. 2013;251(7):1679-1685. doi:10.1007/ s00417-012-2253-8.

99. JMB de B G, Dlc I, MP de Á. Dexamethasone $0.7 \mathrm{mg}$ implants in the management of pseudophakic cystoid 
macular edema. Arq Bras Oftalmol. 2016;79(2):113-115. doi:10.5935/0004-2749.20160033.

100. Ohsugi H, Ikuno Y, Ohara Z, et al. Changes in choroidal thickness after cataract surgery. J Cataract Refract Surg. 2014;40(2):184-191.doi:10.1016/j.jcrs.2013.07.036.

101. Noda Y, Ogawa A, Toyama T, Ueta T. Long-term increase in subfoveal choroidal thickness after surgery for senile cataracts. Am J Ophthalmol. 2014;158(3):455459.e1. doi:10.1016/j.ajo.2014.05.016.

102. Pierru A, Carles M, Gastaud P, Baillif S. Measurement of subfoveal choroidal thickness after cataract surgery in enhanced depth imaging optical coherence tomography. Invest Ophthalmol Vis Sci. 2014;55(8):4967-4974. doi:10.1167/iovs.14-14172.

103. Maruko I, Iida T, Sugano Y, et al. Subfoveal choroidal thickness after treatment of Vogt-Koyanagi-Harada disease. Retina Phila Pa. 2011;31(3):510-517.doi:10.1097/ IAE.0b013e3181eef053.

104. Nakayama M, Keino H, Okada AA, et al. Enhanced depth imaging optical coherence tomography of the choroid in Vogt-Koyanagi-Harada disease. Retina Phila Pa. $\quad$ 2012;32(10):2061-2069.doi:10.1097/IAE.0b013e3182 56205a.

105. Kim M, Kim H, Kwon HJ, Kim SS, Koh HJ, Lee SC. Choroidal thickness in Behcet's uveitis: an enhanced depth imaging-optical coherence tomography and its association with angiographic changes. Invest Ophthalmol Vis Sci. 2013;54(9):6033-6039. doi:10.1167/ iovs.13-12231.

106. Fardeau C, Tran THC, Gharbi B, Cassoux N, Bodaghi B, LeHoang P. Retinal fluorescein and indocyanine green angiography and optical coherence tomography in successive stages of Vogt-Koyanagi-Harada disease. Int Ophthalmol. 2007;27(2-3):163-172. doi:10.1007/s10792006-9024-7.

107. Bouchenaki N, Herbort CP. The contribution of indocyanine green angiography to the appraisal and management of Vogt-Koyanagi-Harada disease. Ophthalmology. 2001;108:54-64.

108. Chu CJ, Johnston RL, Buscombe C, et al. Risk factors and incidence of macular edema after cataract surgery: a database study of 81984 eyes. Ophthalmology. 2016;123 (2):316-323.doi:10.1016/j.ophtha.2015.10.001.

109. Shorstein NH, Liu L, Waxman MD, Herrinton LJ. Comparative effectiveness of three prophylactic strategies to prevent clinical macular edema after phacoemulsification surgery. Ophthalmology. 2015;122(12):2450-2456. doi:10.1016/j.ophtha.2015.08.024.

110. Mathys KC, Cohen KL. Impact of nepafenac $0.1 \%$ on macular thickness and postoperative visual acuity after cataract surgery in patients at low risk for cystoid macular oedema. Eye Lond Engl. 2010;24(1):90-96. doi:10.1038/ eye.2009.10.

111. Tsilimbaris MK, Tsika C, Kymionis GD. Intravitreal ketorolac for the treatment of chronic cystoid macular edema after cataract surgery. Ther Clin Risk Manag. 2016;12:177-182. doi:10.2147/TCRM.S97342.

112. Yüksel B, Uzunel UD, Kerci SG, Sağban L, Küsbeci T, Örsel T. Comparison of subtenon triamcinolone acetonide injection with topical nepafenac for the treatment of pseudophakic cystoid macular edema. Ocul Immunol Inflamm. 2017;25(4):513-519. doi:10.3109/09273 948.2016.1147587.

113. Boscia F, Giancipoli E, D’Amico Ricci G, Pinna A. Management of macular oedema in diabetic patients undergoing cataract surgery. Curr Opin Ophthalmol. 2017;28(1):23-28. doi:10.1097/ICU.0000000000000328.

114. Donnenfeld ED, Holland EJ, Solomon KD, et al. A multicenter randomized controlled fellow eye trial of pulse- dosed difluprednate $0.05 \%$ versus prednisolone acetate 1\% in cataract surgery. Am J Ophthalmol. 2011;152(4):609617.e1.doi:10.1016/j.ajo.2011.03.018.

115. Baartman BJ, Gans R, Goshe J. Prednisolone versus dexamethasone for prevention of pseudophakic cystoid macular edema. Can J Ophthalmol J Can Ophtalmol. 2018;53(2):131-134. doi:10.1016/j.jcjo.2017.08.012.

116. Hudes GR, Li WY, Rockey JH, White P. Prostacyclin is the major prostaglandin synthesized by bovine retinal capillary pericytes in culture. Invest Ophthalmol Vis Sci. 1988;29:1511-1516

117. Shelsta HN, Jampol LM. Pharmacologic therapy of pseudophakic cystoid macular edema: 2010 update. Retina Phila Pa. 2011;31(1):4-12. doi:10.1097/ IAE.0b013e3181fd9740.

118. Conway MD, Canakis C, Livir-Rallatos C, Peyman GA. Intravitreal triamcinolone acetonide for refractory chronic pseudophakic cystoid macular edema. J Cataract Refract Surg. 2003;29:27-33.

119. Simone JN, Whitacre MM. Effects of anti-inflammatory drugs following cataract extraction. Curr Opin Ophthalmol. 2001;12:63-67.

120. Kim SJ, Flach AJ, Jampol LM. Nonsteroidal anti-inflammatory drugs in ophthalmology. Surv Ophthalmol. 2010;55(2):108-133. survophthal.2009.07.005.

121. Benhamou N, Massin P, Haouchine B, Audren F, Tadayoni R, Gaudric A. Intravitreal triamcinolone for refractory pseudophakic macular edema. Am J Ophthalmol. 2003;135:246-249.

122. Bellocq D, Korobelnik J-F, Burillon C, et al. Effectiveness and safety of dexamethasone implants for post-surgical macular oedema including Irvine-Gass syndrome: the EPISODIC study. Br I Ophthalmol. 2015;99(7):979-983. doi:10.1136/bjophthalmol-2014-306159.

123. Ghasemi Falavarjani K, Parvaresh -M-M, Modarres M, Hashemi M, Samiy N. Intravitreal bevacizumab for pseudophakic cystoid macular edema; a systematic review. J Ophthalmic Vis Res. 2012;7:235-239.

124. Nishikawa T, Edelstein D, Du XL, et al. Normalizing mitochondrial superoxide production blocks three pathways of hyperglycaemic damage. Nature. 2000;404 (6779):787-790.doi:10.1038/35008121.

125. Leal EC, Manivannan A, Hosoya K-I, et al. Inducible nitric oxide synthase isoform is a key mediator of leukostasis and blood-retinal barrier breakdown in diabetic retinopathy. Invest Ophthalmol Vis Sci. 2007;48(11):52575265.doi:10.1167/iovs.07-0112.

126. Zheng L, Gong B, Hatala DA, Kern TS. Retinal ischemia and reperfusion causes capillary degeneration: similarities to diabetes. Invest Ophthalmol Vis Sci. 2007;48(1):361367. doi:10.1167/iovs.06-0510.

127. Coscas G, De Benedetto U, Coscas F, et al. Hyperreflective dots: a new spectral-domain optical coherence tomography entity for follow-up and prognosis in exudative age-related macular degeneration. Ophthalmol I Int Ophtalmol Int J Ophthalmol Z Augenheilkd. 2013;229(1):32-37.doi:10.1159/000342159.

128. Madeira MH, Boia R, Santos PF, Ambrósio AF, Santiago AR. Contribution of microglia-mediated neuroinflammation to retinal degenerative diseases. Mediators Inflamm. 2015;2015:673090. doi:10.1155/2015/673090.

129. Block ML, Hong J-S. Microglia and inflammationmediated neurodegeneration: multiple triggers with a common mechanism. Prog Neurobiol. 2005;76(2):77-98. doi:10.1016/j.pneurobio.2005.06.004.

130. Vujosevic S, Bini S, Midena G, Berton M, Pilotto E, Midena E. Hyperreflective intraretinal spots in diabetics without and with nonproliferative diabetic retinopathy: 
an in vivo study using spectral domain OCT. J Diabetes Res. 2013;2013:491835. doi:10.1155/2013/491835.

131. Pang CE, Messinger JD, Zanzottera EC, Freund KB, Curcio $\mathrm{CA}$. The onion sign in neovascular age-related macular degeneration represents cholesterol crystals. Ophthalmology. 2015;122(11):2316-2326. doi:10.1016/j. ophtha.2015.07.008.

132. Cunha-Vaz JG, Travassos A. Breakdown of the bloodretinal barriers and cystoid macular edema. Surv Ophthalmol. 1984;28:Suppl:485-492.

133. Pelosini L, Hull CC, Boyce JF, McHugh D, Stanford MR, Marshall J. Optical coherence tomography may be used to predict visual acuity in patients with macular edema. Invest Ophthalmol Vis Sci. 2011;52(5):2741-2748. doi:10.1167/iovs.09-4493.

134. Sun JK, Lin MM, Lammer J, et al. Disorganization of the retinal inner layers as a predictor of visual acuity in eyes with center-involved diabetic macular edema. JAMA Ophthalmol. 2014;132(11):1309-1316.doi:10.1001/jamao phthalmol.2014.2350.

135. Moein H-R, Novais EA, Rebhun CB, et al. OPTICAL coherence tomography angiography to detect macular capillary ischemia in patients with inner retinal changes after resolved diabetic macular edema. Retina Phila Pa. October 2017. doi:10.1097/IAE.0000000000001902.
136. Spaide RF. Volume-rendered optical coherence tomography of diabetic retinopathy pilot study. Am J Ophthalmol. 2015;160(6):1200-1210. doi:10.1016/j.ajo.2015.09.010.

137. Gaudric A, Coscas G, Bird AC. Choroidal ischemia. Am J Ophthalmol. 1982;94:489-498.

138. Sagoo MS, Mehta H, Swampillai AJ, et al. Primary intraocular lymphoma. Surv Ophthalmol. 2014;59(5):503-516. doi:10.1016/j.survophthal.2013.12.001.

139. B-J C, Dy K, Uc P, Jy L, Yh Y, Hg Y. Clinical features and treatment outcomes of vitreoretinal lymphoma according to its association with cns lymphoma. Ocul Immunol Inflamm. 2018;26(3):365-371. doi:10.1080/09273948. 2017.1421669.

140. Levasseur SD, Wittenberg LA, White VA. Vitreoretinal lymphoma: a 20-year review of incidence, clinical and cytologic features, treatment, and outcomes. JAMA Ophthalmol. 2013;131(1):50-55. doi:10.1001/jamao phthalmol.2013.569.

141. Kim J, Chang W, Sagong M. Bilateral serous retinal detachment as a presenting sign of acute lymphoblastic leukemia. Korean J Ophthalmol KJO. 2010;24(4):245-248. doi:10.3341/kjo.2010.24.4.245.

142. Izzedine H, Fardeau C, Gauthier M, et al. Bilateral serous retinal detachment as a presenting sign of nephrotic syndrome. Intern Med Tokyo Jpn. 2014;53(22):2609-2613. 